\title{
Ruído como agente comprometedor da inteligibilidade de fala dos professores
}

\author{
Valéria de Sá Barreto Gonçalves UFPB \\ Luiz Bueno da Silva UFPB \\ Antonio Souto Coutinho UFPB
}

\begin{abstract}
RESUMO
o objetivo deste artigo é verificar o nível de pressão sonora nas salas de aula e sua interferência na inteligibilidade de fala dos professores. A metodologia utilizada foi do tipo descritivo e exploratório, de natureza qualiquantitativa e efetuada em etapas, a saber: 1) Avaliação do conforto/ desconforto; 2) Avaliação acústica; e 3) Avaliação do desempenho vocal. Como resultado, 94,6\% dos professores afirmaram que é necessário aumentar o tom de voz para haver inteligibilidade de fala; os níveis de pressão sonora variaram entre o mínimo de 46,60 dB ( $A$ ) e o máximo de $87,90 \mathrm{~dB}(\mathrm{~A})$ e o desempenho vocal dos professores esteve entre 49,01 e 83,75 dB (A). Concluiu-se que o baixo rendimento acústico faz com que o professor necessite falar com mais esforço, o que provoca fadiga de fala nos docentes; a origem desse rendimento está vinculada a fontes internas e externas e ao grande número de alunos nas salas de aula.
\end{abstract}

\section{Noise compromising the speech intelligibility for teachers}

\begin{abstract}
The goal of this research is to verify the pressure of noise levels in classrooms and its interference on the intelligibility of teachers' speech. The methodology used was of a descriptive and exploratory, quali-quantitative nature undertaken in stages, namely: 1) Evaluation of the comfort/discomfort; 2) Acoustic evaluation and 3) vocal performance evaluation. The findings showed that 94.6 per cent of the teachers said that is necessary to raise the tone of voice for speech to be intelligible; the level of noise pressure varied between a minimum of $46.60 \mathrm{~dB}(A)$ and a maximum of $87.90 \mathrm{~dB}(A)$; and the vocal performance of the teachers ranged between 49.01 and $83.75 d B(A)$. It concludes that poor acoustics obliges teachers to speak more strenuously, which causes fatigue in the teachers' speech. The cause of this situation is linked to the internal and external sources and the excess of students in classrooms.
\end{abstract}

\section{KEY WORDS}

Intelligibility of speech, noise, teacher, acoustic, vocal performance. 


\section{INTRODUÇÃO}

A conexão entre acústica e arquitetura se dá na pluralidade do melhor aproveitamento do espaço, quando se busca a qualidade de sua ocupação. A relação entre ambas se dá através da estética proporcionada pela "sofisticação" da geometria encontrada, cores, dimensões e funcionalidade, associadas ao conforto ambiental e ao prazer na vivência de sua ocupação.

Para o estudo do comportamento acústico de espaços fechados importa conhecer suas características geométricas, propriedades acústicas, quantidade e posicionamento dos materiais com que foram construídos, dos que os revestem e, principalmente, a orientação e quantidade das aberturas, juntamente com o comportamento do som e a finalidade do espaço.

A acústica arquitetônica lida com sons dentro e ao redor de construções de todos os tipos. Um bom projeto acústico assegura a distribuição eficiente dos sons desejáveis, assim como exclusão dos indesejáveis (ruídos provenientes do telhado, piso, teto e paredes).

Segundo Eniz e Garavelli (2006), o ruído urbano está cada vez mais presente no cotidiano, em residências, locais de trabalho, ambientes de lazer, hospitais e escolas, podendo prejudicar as relações sociais, a comunicação, o comportamento, o rendimento escolar e a saúde das pessoas.

Os ruídos intensos, acima de $90 \mathrm{~dB}(\mathrm{~A})$, dificultam a comunicação verbal. As pessoas precisam falar mais alto e prestar mais atenção para entender e serem compreendidas. Isso faz aumentar a tensão psicológica e o nível de atenção. Os ruídos intensos tendem a prejudicar tarefas que exigem concentração mental e certas tarefas que exigem atenção ou velocidade e precisão de movimentos, e os resultados tendem a piorar após duas horas de exposição ao ruído (IIDA, 1990).

No caso específico de edificações escolares, a qualidade acústica é um item pouco considerado no projeto por arquitetos e engenheiros, apesar da fundamental importância em função do tipo de atividade desenvolvida nesses ambientes.

Menegon (2005) relata que a escola, seja ela de qual nível for, é a instituição que tem por objetivo o ensino de crianças, jovens e adultos. É inegável que exerce importante papel no desenvolvimento dos indivíduos e também da coletividade. Nas edificações que abrigam as escolas é de suma importância que suas dependências estejam dentro de níveis admissíveis de ruídos e sons.

Em uma pesquisa realizada nos EUA pelos doutores Gary Evans e Lorraine (EVANS; MAXWELL, 2000) concluiu-se que alunos de escolas afetadas pelo ruído de aviões não aprendiam a ler tão bem quanto alunos de escolas em regiões mais silenciosas. Deficit na leitura e nas habilidades linguísticas devido a má acústica das salas de aula são cumulativos, assim o efeito sobre estudantes mais jovens é devastador. Como resultado, os alunos têm seu processo de aprendizado prejudicado e os professores ficam sujeitos a uma carga de estresse adicional, o que pode se refletir na qualidade do ensino.

Eniz e Garavelli (2006) afirmam que o ambiente escolar destina-se à produção cultural e formação do cidadão, e que ele pode, por vezes, tornar-se um ambiente ruidoso pela própria atividade de alunos e professores. Dentre os problemas causados pelo ruído, ressaltam-se a falta de concentração, baixa produtividade, interferência na comunicação e dificuldades na aprendizagem de crianças e adolescentes. Segundo Vono-Coube, Belivilacqua e Fernandes (1999), no caso de crianças, o ruído diário pode acarretar problemas de comportamento e distúrbios na voz, além de dificuldade na localização dos sons e no desenvolvimento da fala.

A Organização Mundial da Saúde alerta que um ambiente ruidoso acarreta prejuízos ao desempenho humano e causa danos a saúde geral do indivíduo. Os efeitos observados vão desde fadiga, nervosismo, reações de estresse, ansiedade e falhas de memória até irritabilidade (WHO, 1999).

Lubman e Sutherland (2003) afirmam que a falta de boa acústica na sala de aula pode explicar a dificuldade com a lição de casa de alguns estudantes e o desgaste físico dos professores. As condições acústicas em muitas salas de aula são inadequadas para atividades como aprender a ler, ouvir ou entender uma matéria nova. Nível de ruído elevado ou reverberação excessiva podem frustrar e desencorajar estudantes e professores. Normalmente, professores listam o nível de ruído elevado em seu rol de reclamações. Os estudantes, por sua vez, não notam que as condições acústicas contribuem para dificultar seu aprendizado.

Menegon (2005) relata que atualmente a realidade evidencia a depreciação da qualidade de ensino em consequência de diferentes motivos. $\mathrm{O}$ pouco investimento nas instalações físicas e na infra-estrutura, na qualificação do corpo docente, na implantação de metodologias pedagógicas adequadas e eficientes, na aquisição de materiais ou na manutenção em geral. Dentre os fatores que colaboram para a depreciação, está a qualidade acústica das edificações, aspecto que há muito tempo é pouco considerado e é, mesmo, tratado com descaso. As edificações não evitam a propagação dos sons nem mesmo internamente e não levam em consideração a qualidade acústica interna das salas de aula.

Em questionário aplicado a professores de escolas do Rio de Janeiro, Santos e Slama (1993) concluíram que 50\% dos professores afirmam que o nível de ruído e o espaço físico sempre interferem no rendimento do aluno. Destes, 
$30 \%$ afirmaram que isto ocorre frequentemente e $20 \%$, esporadicamente.

Professores e alunos da cidade de São Paulo são vítimas de situações extremas de poluição sonora nas escolas, normalmente localizadas próximo de locais ruidosos, como grandes avenidas. A constatação vem de um levantamento previamente realizado em escolas municipais pela equipe de Saúde Auditiva da Prefeitura. Nessas escolas, durante o recreio, o nível de ruído chegou a atingir $105 \mathrm{~dB}(\mathrm{~A})$, quase o mesmo nível de um helicóptero $(110 \mathrm{~dB}(\mathrm{~A}))$ ao pousar. Mesmo nas salas em que os alunos se mantiveram em silêncio, o nível de ruído ficou, na média, em $80 \mathrm{~dB}(\mathrm{~A})$.

Segundo Menegon (2005), não apenas os problemas auditivos que provocam baixo aproveitamento ou reprovação escolar. A dificuldade em isolar diversos parâmetros que podem influenciar no desempenho acadêmico torna a questão bastante complexa.

Em uma escola, diversos problemas que afetam alunos e professores podem ser encontrados: conforto ambiental, aspectos sociológicos, pedagógicos e até mesmo políticos. No conforto ambiental, uma das variáveis importantes é o nível de ruído. Nesse artigo procurou-se avaliar o ruído como agente que pode comprometer a inteligibilidade de fala de professores das escolas municipais da cidade de João Pessoa (PB).

\section{REVISÃO DA LITERATURA}

Hoje, a preocupação acústica não é apenas uma questão de condicionamento acústico do ambiente mas também de controle de ruído e preservação da qualidade ambiental. A questão acústica tornou-se mais importante porque o número de fontes produtoras de ruído é cada vez maior e suas consequências para o homem são cada vez mais prejudiciais (SOUZA, 2003).

Níveis de ruído elevados e/ou condições de reverberação inadequadas prejudicam o processo de aprendizagem chegando, até, a contribuir para o baixo aproveitamento dos alunos. Em relação aos professores, o não atendimento de critérios de conforto acústico faz com que tenham de fazer esforço vocal excessivo, mesmo que este não garanta melhor inteligibilidade de fala. Paralelamente, a normatização afeta ao tema está muito aquém do desejado, não existindo recomendações adequadas em nível nacional. A situação demanda urgentemente o estabelecimento de parâmetros mínimos de aceitabilidade do nível de ruídos em edificações escolares (MENEGON, 2005).

Alguns problemas relacionados à voz do professor decorrem de detalhes acústicos das salas de aula. O tempo que o nível de pressão sonora leva para ser absorvido em uma sala de aula é chamado de reverberação, a qual é influenciada pelo volume e pela capacidade dos materiais usados nas paredes, piso e teto de absorverem a energia sonora.

A ANSI/ASA S12.60 (ANSI, 2002) da Sociedade Americana de Acústica levantou algumas considerações sobre o aumento do ruído em salas de aula:

- O tempo de reverberação deve ser reduzido instalandose materiais absorventes nas paredes e no teto;

- O ruído urbano aumentou devido ao crescimento das cidades, mas a tecnologia de fabricação de portas e janelas de isolamento do ruído externo não evoluiu proporcionalmente.

Silva (1991) cita que o atendimento às condições acusticamente adequadas para o trabalhador redunda na diminuição de faltas, por doenças ou acidente, com consequente aumento da produtividade, caso em que o professor se enquadra plenamente.

Santos (1999) menciona que o absenteísmo, a cefaléia e a alta incidência de acidentes de trabalho são consequências da exposição prolongada ao ruído. O custo

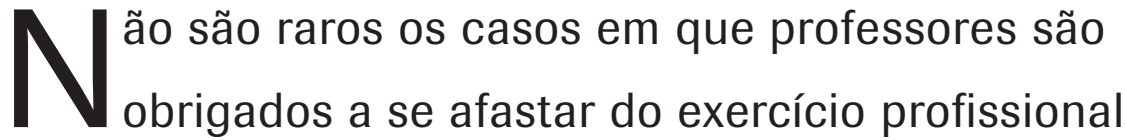

social envolvido torna-se bastante elevado, pois profissionais deixam de exercer a sua profissão e alunos, de receber educação adequada.

A ANSI aprovou em junho de 2003 o padrão de referência com critérios de desempenho e exigências do projeto acústico para escolas. Critérios, exigências e orientações foram formatados para obter grau elevado de inteligibilidade nos espaços destinados à aprendizagem (ROMAN, 2005). As normas DIN 18041 - Schallschutz in Schulen (DEUTSCHES INSTITUT FÜR NORMUNG, 1998) Schallschutz in Schulen (controle de ruído em escolas) e NBR 10152 (ABNT, 1987) recomendam que salas de aula com boas condições acústicas devem ter de 4 a $5 \mathrm{~m}^{3}$ por aluno.

A NBR 10152 (ABNT, 1987) estabelece os níveis de pressão sonora considerados de conforto acústico no ambiente construído. Esse nível sonoro dentro da sala de aula desocupada deve estar entre 40 e $50 \mathrm{~dB}(\mathrm{~A})$, sendo que o valor inferior representa o nível de conforto, enquanto o superior, desconforto.

Com relação à produção vocal dos professores, a voz é produzida na laringe, através da liberação de ar dos pulmões para o trato vocal, de modo que o ar é conduzido para fora dos pulmões através da traquéia, passando pela laringe. 
A voz possui características individualizadas do ser humano e qualquer alteração no comportamento vocal é facilmente identificada pelo ouvinte (BEHLAU; PONTES, 1995). As modificações da configuração e, portanto, das propriedades acústicas dessas cavidades, que são conhecidas como trato vocal, transformam o som glótico em sons de fala com significado.

Não são raros os casos em que professores são obrigados a se afastar do exercício profissional ou até mesmo a diminuir sua carga de trabalho para recuperar a capacidade de fala.

Segundo Pereira (2002), o professor universitário Wilson Brinkmann, hoje com 60 anos de idade, lecionando comunicação social há cerca de 27 anos, relata que há cinco anos, uma tosse com pigarro o acompanha constantemente. Se a situação causa incômodo a qualquer pessoa, versitário cujo principal instrumento de trabalho é a voz. Os distúrbios de voz causados pelo exercício da profissão que acometeram o professor Brinkmann estão presentes no cotidiano de muitos outros professores. Eles dão aulas em salas lotadas e inalam pó de giz; somam-se a esses fatores o ruído proveniente da rua, do condicionador de ar e das conversas dos alunos. "A acústica das salas da universidade onde leciono é péssima", desabafa o professor".

Com base em uma pesquisa norte-americana feita por Nelson Roy, da University of Utah, as fonoaudiólogas Fabiana Zambon, do Sindicato dos Professores de São imagine-se o efeito desse incômodo para um professor uni-

dia de trabalho, com frequência à noite. A rouquidão acomete $29 \%$ do grupo. Quanto maior o número de alunos, maiores as chances de desenvolver distúrbios vocais.

Ainda em relação à pesquisa, dos 217 entrevistados, $85 \%$ dos professores têm hábitos saudáveis e não fumam e $76 \%$ não ingerem bebidas alcoólicas regularmente. "O problema é ocupacional, daí a necessidade de uma lei que garanta ao professor melhores condições de trabalho", afirma Rita Fraga ${ }^{2}$, diretora do SINPRO-SP, que verificou também a ausência de uma Comissão Interna de Prevenção de Acidentes (CIPA), a qual tem entre suas funções orientar e prevenir problemas de voz em professores.

Segundo o SINPRO-SP, a atividade profissional do professor revela-se um fator de risco para o surgimento de lesões que acometem as estruturas corporais. Essas lesões acabam afetando a realização plena das atividades docentes gerando, por vezes, incapacidades temporárias ou permanentes. Nos casos mais graves pode gerar afastamento da escola e das atividades profissionais.

Os maiores danos ocasionados estão relacionados com problemas vocais. A comunicação faz parte da atividade docente e é através dela que professor exerce sua função como educador. Portanto, qualquer problema em sua capacidade de transmissão de conhecimento acarretará prejuízos não somente ao professor mas também aos alunos, que terão dificuldades maiores para apreender o que está sendo lecionado.

\section{acústica inadequada das salas de aula cria condições
ruins de aprendizagem para muitos estudantes}

Paulo (SINPRO-SP), e Mara Behlau, do Centro de Estudos da Voz de São Paulo (CEV-SP), iniciaram uma pesquisa com professores para verificar os problemas de voz que a profissão acarreta.

Esta pesquisa foi divulgada pela Universidade Federal de São Paulo (UNIFESP) e a Subdelegacia Regional do Trabalho da Zona Norte de São Paulo, onde um levantamento realizado com 217 professores de três universidades privadas dessa região da cidade revelou os principais problemas vocais e as condições que, no ambiente profissional, atuam como fatores de risco.

Como resultado, constatou-se que cerca de $60 \%$ dos professores que responderam ao questionário de autoavaliação - 120 homens e 97 mulheres na faixa de 35 a 40 anos não adotam nenhuma técnica de "cuidado" com a voz. Eles abrem mão do microfone em salas lotadas e não tomam água durante as aulas para hidratar as pregas vocais. Mesmo ao sentir os primeiros sinais de irritação, $83 \%$ declararam não ter procurado um especialista. E, ainda, $76 \%$ sentem dor ou irritação na garganta e $61 \%$ têm variações na voz durante o
$\mathrm{O}$ alto nível de ruído, acima de $60 \mathrm{~dB}(\mathrm{~A})$, faz com que o profissional docente necessite elevar o nível de intensidade de sua voz para que os alunos ouçam o que esta sendo proferido. Naturalmente que este nível elevado, acima do normal, mais cedo ou mais tarde, causará fadiga. Com o passar dos anos, o professor começa a perceber problemas como: rouquidão, dores nas pregas vocais e na laringe, perda da capacidade normal da fala, além de outros problemas indiretos, como perda da capacidade de concentração dos alunos por problemas no entendimento, efeitos colaterais diversos como dores de cabeça, efeitos psicológicos pela incapacidade de exercer a função de maneira adequada, dentre outros.

Fabiano e Brasoloto (1998) afirmam que os professores estão entre os dez profissionais que mais procuram ajuda médica em decorrência de problemas vocais. Tratamentos fonoaudiológicos são necessários, mas não são a solução, pois de nada adianta, depois de afastado e recuperado, obrigar o professor voltar ao mesmo e inalterado ambiente de trabalho que causou o problema. Assim, é necessário corrigir a causa, caso contrário haverá não somente risco

\footnotetext{
$\overline{1,2}$ Fonte: Sinpro-SP, http://www.sinprosp.org.brpublicacoes.asp
} 30/05/2006 
de perda do tratamento, mas também de que qualquer outro professor exposto à mesma situação acabe por ter os mesmos problemas vocais.

Penteado e Pereira (1996) afirmam que o indivíduo com distúrbios vocais sofre limitações de ordem física, emocional e até mesmo profissional, dada a relevância da comunicação no papel desempenhado por ele.

Anjos (1999), em seu estudo sobre incidência de disfonia em professores, afirma que após a utilização de voz por horas seguidas podem ocorrer modificações vocais caracterizadas acusticamente pelo espectro, com diminuição de energia na proporção harmônicos/ruído e modificações na frequência fundamental. Auditivamente, a voz pode apresentar perda de projeção, agravamento, rouquidão e outras características.

Além de ser uma fonte de estresse, o ruído provoca uma série de reações físicas e psíquicas. Entre os problemas registrados estão: perda da concentração, aumento da frequência cardíaca e dificuldade de conciliar o sono.

Segundo Neto (2001), como resultado da contínua exposição dos alunos e professores a níveis altos de ruído em ambientes escolares, em uma das escolas selecionadas para o levantamento da Secretaria Municipal da Saúde na região do Butantã-Lapa (RJ) em 1996, constatou-se que em média $36 \%$ dos professores e $17,4 \%$ dos alunos apresentavam alguma alteração na audição. Esse autor enfatizou que as escolas são mal planejadas, funcionam como verdadeiras caixas de reverberação aos ruídos produzidos do lado de fora, pelo tráfego intenso, e também para o próprio ruído produzido internamente pelos alunos. É preciso levar em conta fatores como localização e arquitetura, que podem aumentar ou diminuir a poluição sonora nas escolas, que muitas delas ficam perto de avenidas movimentadas ou rodovias, com as janelas voltadas para a via, sem barreiras de isolamento. No Brasil, a acústica das salas de aula ainda é considerada sem importância diante de tantas outras precariedades na área de educação.

Vono-Coube, Belivilacqua e Fernandes (1999) citam o caso de duas crianças que foram acompanhadas durante 10 horas seguidas e observou-se que o ruído médio foi de $78 \mathrm{~dB}(\mathrm{~A})$ para uma das crianças e de $75 \mathrm{~dB}(\mathrm{~A})$ para a outra. Os valores mais elevados de ruído ocorreram no período em que as crianças permaneceram na escola. Assim, verificou-se que a voz normal do professor sempre está em um nível inferior ao ruído do ambiente da sala de aula, impossibilitando o aluno compreender melhor a mensagem passada por ele. Para sanar esse problema em sala de aula, o professor precisará elevar sua voz, provocando um desgaste vocal ainda maior.

A acústica inadequada das salas de aula cria condições ruins de aprendizagem para muitos estudantes, especialmente aqueles que apresentam deficiências auditivas ou de aprendizagem. "As condições acústicas em muitas salas de aula são incompatíveis com tarefas como aprender a ler, escutar ou compreender assuntos com os quais não se esteja acostumado"3. A acústica ruim das salas de aula é frustrante tanto para estudantes como para professores. Em várias salas de aula nos Estados Unidos, até $25 \%$ da informação pode ser perdida por causa do ruído e da reverberação (EVANS; MAXWELL, 2000).

Quando o ruído é combinado com a reverberação, o entendimento da fala torna-se difícil. Pode-se concluir que, para manter alta inteligibilidade de fala, o tempo de reverberação em salas com níveis consideráveis de ruído deveria ser menor do que o tempo de reverberação em lugares silenciosos.

De acordo com Seep (2002), reverberação e ruído em excesso interferem na inteligibilidade da fala, resultando na redução do entendimento e, portanto, na redução do aprendizado. A presença de ruído durante o processo de comunicação diário causa, muitas vezes, dificuldades na percepção da fala e grandes níveis de estresse, até mesmo em pessoas com audição normal (SOCINI; COSTA; OLIVEIRA, 2003).

A inteligibilidade de fala é definida como a relação entre palavras faladas e palavras entendidas expressa em porcentagem. Para que a comunicação seja efetiva e inteligível, a inteligibilidade da fala deve ser superior a $90 \%$ (NEPOMUCENO, 1994). Mas ressalta-se que a inteligibilidade de $100 \%$ das palavras fáceis exige uma intensidade de voz de $10 \mathrm{~dB}(\mathrm{~A})$ acima do ruído de fundo, que nas cidades brasileiras geralmente passa dos $70 \mathrm{~dB}(\mathrm{~A})$. Isto pode estressar as pregas vocais de quem fala e incompatibilizar as condições de concentração para atividades mentais e psicológicas de quem escuta (PIMENTEL-SOUZA, 1992).

Para Fernandes (2000), o conceito de inteligibilidade quando se refere à comunicação em um ambiente é definido como "inteligibilidade acústica da linguagem". É a principal característica acústica de um ambiente, pois reflete o grau de entendimento das palavras no seu interior. Para locais onde a comunicação é primordial (auditórios, cinemas, teatros, igrejas, salas de aula e de conferências, etc.) a boa inteligibilidade acústica é um fator decisivo.

A inteligibilidade de fala em salas de aula é influenciada, segundo Nábělek, A. e Nábělek, I. (1997), por três fatores: o nível da fala, a reverberação da sala e o ruído de fundo. A importância de cada um destes depende da distância entre o ouvinte e a fonte sonora, porque o nível dos sons diretos e refletidos e o ruído de fundo variam ao longo da sala. Para uma boa inteligibilidade, a intensidade de fala diminui de acordo com a distância da fonte; a modificação da fala frequentemente pode ser necessária, especialmente em salas amplas.

3 Fonte: Sinpro-SP, http://www.sinprosp.org.brpublicacoes.asp 30/05/2006 
O Nível de Pressão Sonora (NPS) dentro de uma sala, proveniente de fontes de ruído externo, depende da intensidade desses ruídos, das propriedades de isolamento sonoro das divisórias que cercam a sala e da absorção sonora da sala. Os materiais de absorção servem para dois propósitos: reduzem o tempo de reverberação e reduzem o nível de ruído de fundo. Em uma sala de aula, o som da fala direta está misturado com o som da reverberação e com o ruído de fundo. Se o ruído estiver misturado com a fala, então algumas partes da fala encobertadas pelo ruído se tornarão inaudíveis, ou mascaradas. Os efeitos globais do ruído na percepção da fala-ruído (F/R) são expressos em $\mathrm{dB}$. As pontuações de reconhecimento da fala são geralmente altas quando a relação $F / R$ é alta, e baixas quando a relação $F / R$ é baixa (NÁBĔLEK, A.; NÁBĔLEK, I., 1997).

Pearsons et al. (1977) informaram que a média ponderada da curva A (nível de apresentação do ruído na orelha humana), dos níveis de ruído de fundo em escolas e em residências deveriam estar entre $45 \mathrm{~dB}$ e $55 \mathrm{~dB}$. Com o nível médio de fala de aproximadamente $65 \mathrm{~dB}$ medido a uma distância de $1 \mathrm{~m}$ da boca do falante, a relação $\mathrm{F} / \mathrm{R}$ em escolas e residências situa-se por volta de $+10 \mathrm{a}+20 \mathrm{~dB}$, isto é, o nível de fala é 10$20 \mathrm{~dB}$ mais alto do que o nível de ruído. Os autores relatam que os professores tendem a elevar a voz quando o nível de ruído é elevado, de forma a manter a média de $\mathrm{F} / \mathrm{R}$ em torno de $+15 \mathrm{~dB}$. Não é sensato esperar que os professores elevem constantemente a voz para superar níveis excessivos de ruído.

A manutenção constante da voz elevada por anos de trabalho pode provocar a deterioração da audição. O HDI (hearing deterioration index), conforme pode se ver na Figura 1, em que $L$ é o nível médio de ruído em $\mathrm{dB}(\mathrm{A})$ e $t$ é o tempo de exposição em anos, assume exposição de

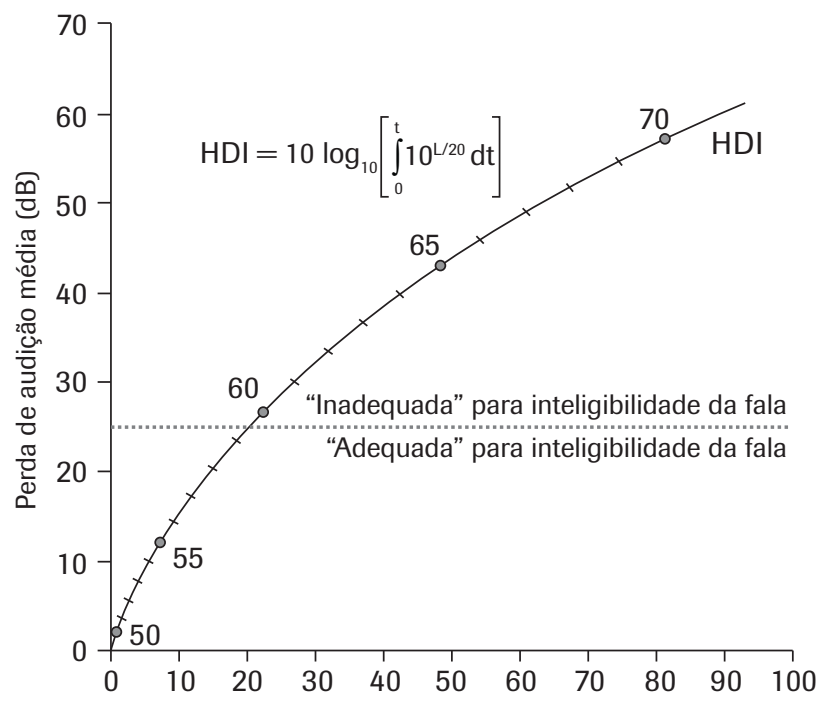

Figura 1: Risco de perda de audição. Fonte: Bies e Hansen (2002)
$1.900 \mathrm{~h} /$ ano no nível $L$. A Figura 1 indica que para se evitar perda de audição de $80 \%$ da população deve-se adotar uma estratégia que previna a aquisição de HDI maior que 59 durante a vida. Por exemplo, se pessoas com 20 anos de experiência trabalham em ambientes onde o nível de ruído médio está em torno de $90 \mathrm{~dB}(\mathrm{~A})$, tem-se um $\mathrm{HDI}=58 . \mathrm{Ou}$ seja, para essas condições, $15 \%$ dessas pessoas apresentarão $20 \mathrm{~dB}$ de perda de audição devido à exposição ao ruído. Vale lembrar que a ferramenta principal de um professor é a voz; às vezes ela é utilizada em mais de um turno de trabalho, durante pelos menos 35 anos.

A norma ANSI/ASA S12.60 (ANSI, 2002) tem como objetivo obter uma inteligibilidade ótima (I > 90\% ou $\mathrm{S} / \mathrm{N}>10 \mathrm{~dB}$ ) em ambientes de ensino (Tabela 1). Para isso, impõe limites para três parâmetros acústicos da sala de aula: limita o ruído de fundo e o tempo de reverberação e especifica o menor valor aceitável para transmissão sonora entre ambientes adjacentes. Essa norma estabelece valor mínimo de 35 e máximo de $40 \mathrm{~dB}$ para o ruído de fundo de salas de aula (inclusive com o sistema de ar condicionado ligado). Em momentos de maior ruído, a norma especifica que a média, em uma hora, não deve ultrapassar $40 \mathrm{~dB}(\mathrm{~A})$ em mais de $10 \%$ do tempo. Para o tempo de reverberação, indica que esse tempo em sala de aula deve estar entre 0,4 e 0,6 s. Para espaços acima de $10.000 \mathrm{ft}^{3}\left(283 \mathrm{~m}^{3}\right)$, não deve exceder $0,6 \mathrm{~s}$, e para salas com volume entre $10.000 \mathrm{ft}^{3}$ $\left(283 \mathrm{~m}^{3}\right)$ e $20.000 \mathrm{ft}^{3}\left(566 \mathrm{~m}^{3}\right)$, não deve exceder $0,7 \mathrm{~s}$.

\section{METODOLOGIA}

A pesquisa que proporcionou o desenvolvimento do presente artigo foi aprovada pelo Comitê de Ética em Pesquisa da Universidade Federal da Paraíba em março de 2008, visto tratar-se de investigação envolvendo seres humanos, e está devidamente regulamentada segundo resolução do Conselho Nacional de Saúde 196/96.

Esta investigação trabalhou com dados primários acerca do conforto acústico de 37 salas de aula e do desempenho

Tabela 1: Valores aceitáveis de inteligibilidade. Fonte: ANSI S12.60 (2002)

\begin{tabular}{cc}
\hline Valores da Inteligibilidade & Qualidade acústica \\
\hline $\mathrm{I} \geq 90 \%$ & Ótima \\
$85 \% \leq \mathrm{I}<90 \%$ & Muito boa \\
$80 \% \leq \mathrm{I}<85 \%$ & Boa \\
$75 \% \leq \mathrm{I}<80 \%$ & Satisfatória \\
$70 \% \leq \mathrm{I}<75 \%$ & Regular \\
$60 \% \leq \mathrm{I}<70 \%$ & Má \\
$\mathrm{I}<60 \%$ & Inaceitável \\
\hline
\end{tabular}


vocal de 37 professores. A avaliação dos Níveis de Pressão Sonora (NPS) realizou-se in situ e a avaliação do desempenho vocal, em sala silenciosa, conforme descrito nas seguintes etapas:

\section{$1^{\text {a }}$ etapa: Avaliação do conforto/desconforto}

A avaliação do grau de conforto/desconforto acústico dentro das salas de aula se deu transversalmente a partir das respostas dos professores a um formulário, obtidas através de entrevista direta. Esse instrumento de pesquisa (formulário) adaptado para este estudo foi desenvolvido por Menegon (2005), que o aplicou em um estudo realizado em escolas na cidade de Bauru, São Paulo, verificando em que medida o ruído nessas escolas poderia gerar problemas de saúde em alunos e professores.

O formulário está dividido em três sessões: a primeira relativa à autopercepção dos sinais e sintomas da voz do professor - possíveis problemas que afetam o desempenho desses profissionais: desgaste vocal, aumento do tom de voz, excesso de ruídos, voz rouca, dores de cabeça, estresse, dores de garganta e problema com ruídos em sala de aula; a segunda relativa ao conforto acústico das salas de aula às fontes de ruídos internas e externas às salas de aula; a terceira e última sessão refere-se aos alunos - observações vinculadas à inteligibilidade de fala. Esse formulário foi utilizado com o objetivo de traçar um perfil com as características da amostra.

\section{$2^{a}$ etapa: Avaliação acústica}

Para medir os níveis sonoros equivalentes empregou-se um medidor constituído por um amplificador e um indicador de nível de pressão sonora de marca Instrutherm, modelo SL 4011, fabricado pela Instrutherm Instrumentos de Medição Ltda. Esse equipamento atende os parâmetros de normalidade exigidos pela legislação brasileira em vigor para cálculo do NPS. Ele é composto por um circuito de ponderação "A", circuito de resposta "lenta - SLOW", circuito de referência de $85 \mathrm{~dB}$, faixa de medição entre 50 e $115 \mathrm{~dB}(\mathrm{~A})$.

Foram coletados os 30 maiores picos de ruído distribuídos em três pontos estratégicos de cada sala, como mostra a Figura 2, em horário de aula, medidos a cada 0,015 s. O mesmo procedimento foi efetuado em salas sem atividade, com janelas fechadas.

Para avaliação dos NPS no posto de trabalho foi utilizada a dose projetada. Após ter sido coletado o ruído no interior das salas de aula em atividade, foram efetuados os cálculos referentes a oito horas de exposição e determinado quanto desse ruído chegava à orelha humana. Este dado propõe verificar se os NPS coletados no interior das salas em plena atividade podem causar perdas auditivas induzidas por níveis elevados de pressão sonora.

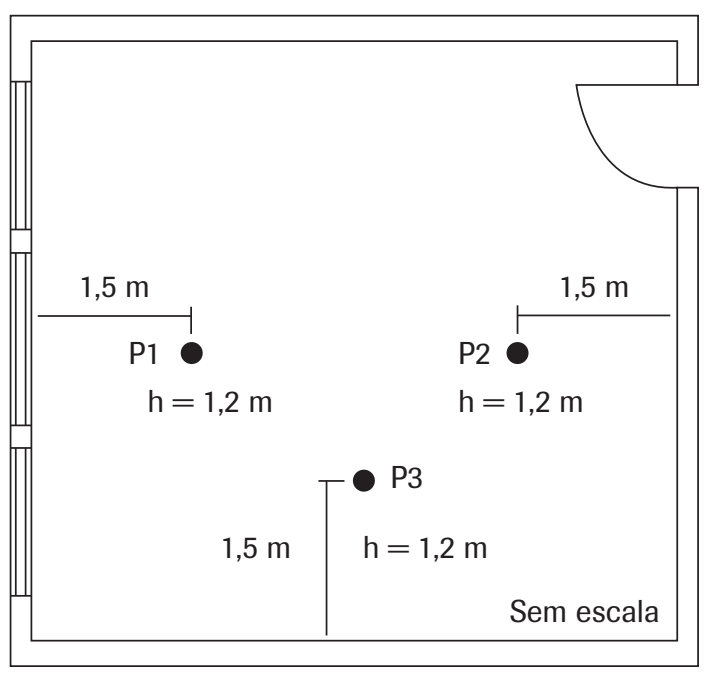

Figura 2: Pontos de medida nas salas. Fonte: pesquisa direta (2007)

\section{$3^{\text {a }}$ etapa: Desempenho vocal}

A avaliação do desempenho vocal dos professores foi efetuada de forma objetiva, através das funções de qualidade vocal. As medições referem-se ao uso da voz e foram feitas em salas em silêncio.

A avaliação do desempenho vocal foi efetuada em uma sala silenciosa cedida por cada instituição pesquisada. Foi pedido a cada professor que emitisse as vogais $/ \mathrm{a} /, / \mathrm{i} / \mathrm{e} / \mathrm{u} /$, as consoantes /s/ e /z/ e realizasse a emissão prolongada da vogal /e/. Esses dados complementaram os coletados para aferição dos NPS.

A avaliação vocal da emissão prolongada da vogal /e/ foi analisada através do programa de microprocessador Voxmetria versão 2.8 , produzido pela CTS Informática Softwares. Este programa apresenta o diagrama de desvio fonatório, oferece um gráfico visual simples e direto que posiciona a emissão vocal dentro de uma região normal ou alterada. Apresenta, também, tratamento estatístico que utiliza valores obtidos para a análise dos índices de perturbação a curto prazo; essas aferições de ruído permitem analisar o componente harmônico e o grau de regularidade da emissão. Para realização do teste, o microfone esteve posicionado em um ângulo de $45^{\circ}$ a $90^{\circ}$ da boca do indivíduo e mantido a uma distância de cerca de $5 \mathrm{~cm}$.

A partir da análise demonstrativa de todas as etapas anteriores foi desenvolvido um estudo apresentando os achados da pesquisa e demonstrando como esses resultados podem contribuir para reflexão e mudança de conduta com relação ao ruído constatado nos ambientes escolares. Todos os dados coletados foram interpretados e tabulados para a análise e conclusão da pesquisa. 
Esta pesquisa caracteriza-se por ser qualiquantitativa, pois os dados coletados foram analisados segundo a percepção vocal dos docentes e segundo as medições realizadas. Tais procedimentos foram realizados no Laboratório de Métodos Quantitativos Aplicados - LabMEQA do Departamento de Engenharia de Produção.

Para avaliação dos formulários, foi adotado o seguinte procedimento analítico: após coletados os dados, estes foram transportados para uma planilha; o tratamento estatístico valeu-se do software Statical Package for the Social Sciences (SPSS), versão 14.0, para uso em microprocessador. Por isso, a distribuição numérica e percentual consistiu na distribuição dos dados em gráficos e tabelas expostos na análise e discussão a seguir. Para tratamento dos dados, os formulários foram numerados e todas as variáveis codificadas em um banco de dados eletrônico. Para avaliação de Leq, segundo a NBR 10151 (ABNT, 2000), aplicou-se a Equação (1).

Leq $=10 \log \left(\frac{1}{N} \sum_{i=1}^{N} 10^{0,1 L i}\right)$

Onde:

Leq - nível de pressão sonora equivalente, em $\mathrm{dB}(\mathrm{A})$;

$L i$ - nível de pressão sonora medido a cada instante "i", em $\mathrm{dB}(\mathrm{A})$;

$\mathrm{N}$ - número total de medições.

\section{RESULTADOS}

De acordo com a Figura 3, 91,9\% dos professores afirmaram que ao ministrar as aulas um problema muito perceptível é o ruído em sala, que pode interferir no desempenho. E,

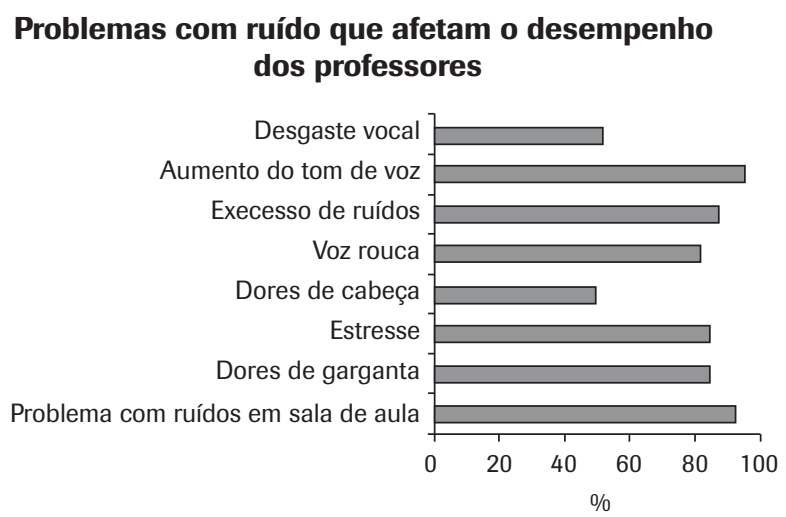

Figura 3: Avaliação do grau de conforto/desconforto acústico dos professores.

Fonte: Pesquisa direta (2007) ainda, 94,6\% dos professores afirmaram que devido ao ruído no ambiente é necessário que aumentem seu tom de voz para que haja inteligibilidade de fala na sala de aula. Outros sintomas como desgaste vocal $(51,4 \%)$, dores de garganta $(83,8 \%)$, voz rouca $(81,1 \%)$, dores de cabeça $(48,6 \%)$ e estresse $(83,8 \%)$ são citados pelos profissionais como decorrentes do desgaste físico provocado pelo ruído em sala de aula. Esses sintomas podem interferir diretamente no desempenho vocal do professor, que ao final de cada dia de trabalho sente em seu organismo o desgaste acumulado durante a jornada.

Entre as variáveis termofísicas relacionadas às condições ambientais que podem interferir no conforto ambiental estão: temperatura, ruído e iluminação. Observa-se que, entre essas variáveis, $83,8 \%$ dos professores entrevistados apontam o ruído como o fator que mais causa desconforto na realização de atividades em sala de aula. Diante deste fato, o problema: o impacto do ruído pode ser o grande causador de desgaste e fadiga vocal dos professores, contribuindo para a queda de produtividade desses profissionais e de seus alunos. Esta constatação pode ser observada na Tabela 2.

A Figura 4 apresenta o comportamento do nível de ruído medido no posto de trabalho do professor que trabalha oito horas diárias. Os resultados indicam valor mínimo de 48,40 dB(A) e máximo de $81,20 \mathrm{~dB}(\mathrm{~A})$.

Comparados à legislação em vigor, segundo a portaria 3.214/78 (BRASIL, 1978) Anexo I da Norma Regulamentadora NR-15, os valores indicam um ambiente salubre. Porém, a Organização Mundial de Saúde - OMS (WHO, 1980) afirma que acima de $65 \mathrm{~dB}(\mathrm{~A})$ o ruído pode perturbar o trabalho, o descanso, o sono e a comunicação, e pode prejudicar a audição e causar ou provocar reações psicológicas, fisiológicas e patológicas.

A Tabela 3 mostra aferições do ruído de fundo nas salas de aula e o desempenho vocal dos professores. O ruído de fundo apresentou valor mínimo de $46,6 \mathrm{~dB}(\mathrm{~A})$ e máximo de $87,9 \mathrm{~dB}(\mathrm{~A})$, conflitando com a resolução do CONAMA n. ${ }^{\circ} 001$ (1990) e com a resolução da ANSI/ ASA S12.60 (2002), que estabelecem valor mínimo de 35 e máximo de $40 \mathrm{~dB}(\mathrm{~A})$ para o ruído de fundo em salas de aula.

Tabela 2: Distribuição das condições ambientais na sala de aula.

Fonte: Pesquisa direta (2007)

\begin{tabular}{lrc}
\hline Condições ambientais & \multicolumn{1}{c}{$f_{\mathrm{i}}$} & $\%$ \\
\hline Iluminação & 2 & 5,4 \\
Ruído & 31 & 83,8 \\
Temperatura & 4 & 10,8 \\
Total & 37 & 100,0 \\
\hline
\end{tabular}




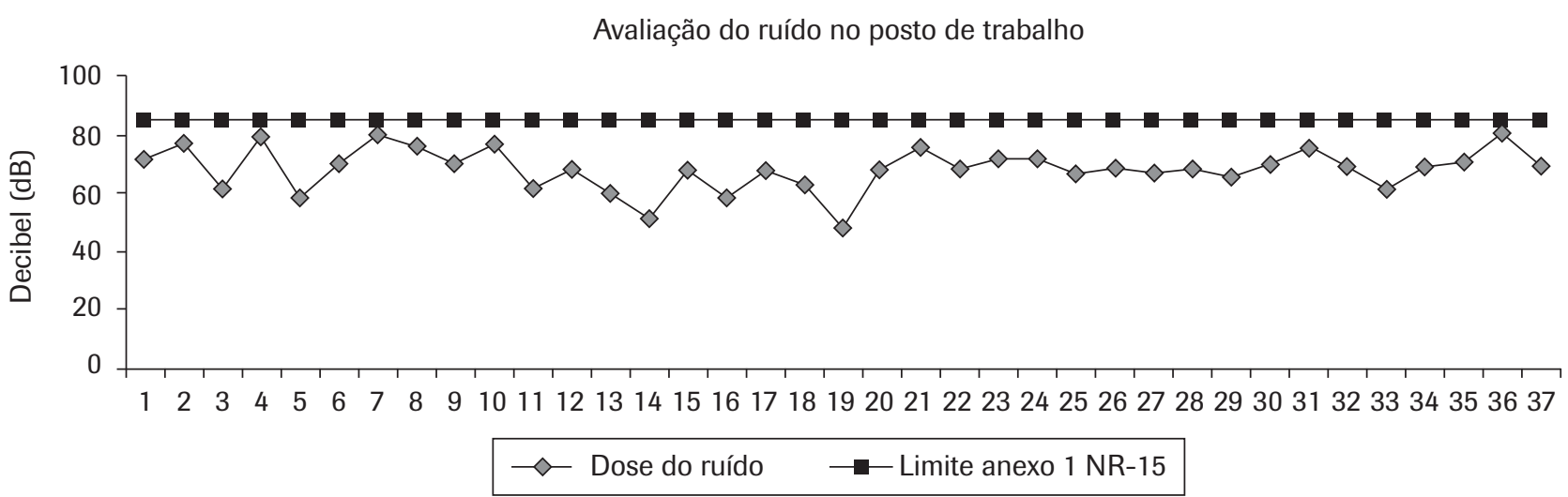

Figura 4: Avaliação do ruído no posto de trabalho.

Fonte: Pesquisa direta (2007)

Simulação do desempenho vocal ideal para essas escolas

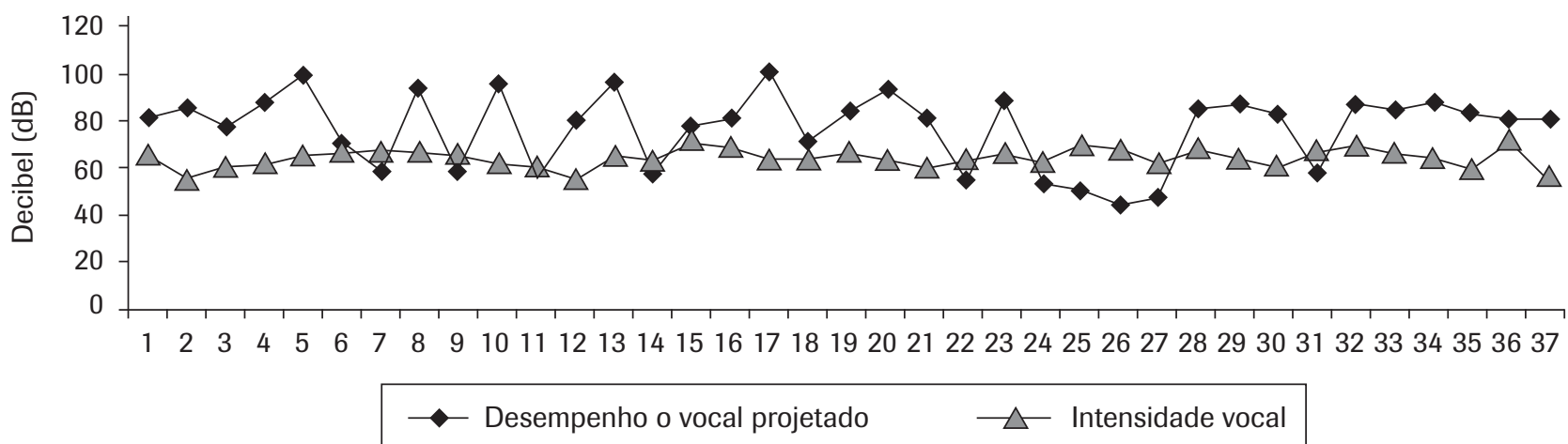

Figura 5: Simulação do desempenho vocal ideal para essas escolas.

Fonte: Pesquisa direta (2007)

Tabela 3: Distribuição em dB(A) do Desempenho Vocal (DV). Fonte: Pesquisa direta (2007)

\begin{tabular}{lccc}
\hline Ruído de Fundo $-\mathrm{dB}(\mathrm{A})$ & Mínimo & Média & Máximo \\
\hline Ruído de fundo & 46,60 & 67,25 & 87,90 \\
Desempenho Vocal (DV) & 49,01 & 66,38 & 83,75 \\
DV recomendado & 50,00 & - & 70,00 \\
DV ideal para estas escolas & 56,60 & 77,25 & 97,90 \\
\hline
\end{tabular}

Ainda na Tabela 3 pode-se ver que a intensidade do desempenho vocal dos professores foi de 49,01 $\mathrm{dB}(\mathrm{A})$ a $83,75 \mathrm{~dB}(\mathrm{~A})$. Segundo Behlau et al. (2005), valores aceitáveis para produção vocal situam-se entre 50 e $70 \mathrm{~dB}(\mathrm{~A})$. Como o desempenho vocal ideal é o ruído de fundo mais $10 \mathrm{~dB}(\mathrm{~A})$, os níveis ideais para o desempenho vocal dos professores no exercício da docência nessas salas de aula deveria variar entre 56,60 dB(A) (mínimo) e 97,9 dB(A) (máximo), o que extrapola o intervalo que o aparelho fonador humano abrange. Essa diferença entre o desempenho vocal dos professores e o aumento desse desempenho pode também ser visualizada na Figura 5.

\section{CONCLUSÃO}

A longa jornada de trabalho do professor implica no uso da voz por muitas horas seguidas; o excesso de trabalho, que obriga o professor a levar atividades para casa e diminuir o seu tempo de repouso e lazer; o número excessivo de alunos em sala de aula, que também obriga o professor a aumentar a intensidade da voz para ser ouvido por todos na sala; a indisciplina dos alunos, que gera desgaste adicional para o profissional; as inadequadas condições físicas de trabalho, como salas de aula mal projetadas, ruído externo e interno à sala; salas de professores com estrutura inadequada; a falta de informações sobre os necessários cuidados com a saúde vocal na formação profissional do professor; 
todas essas situações fazem com que o professor seja um dos profissionais que mais apresenta problemas vocais.

Frequentemente, professores relatam queixas do tipo: garganta raspando e ardendo; sensação de corpo estranho na garganta; tensão no pescoço; cansaço vocal; voz mais fraca no final do dia; alterações na qualidade vocal; entre outros sintomas que denunciam uso inadequado das estruturas que produzem a voz e/ou o abuso vocal.

Nessa pesquisa foi possível concluir que, para as condições ambientais, os NPS variaram entre 46,60 dB(A) e $87,90 \mathrm{~dB}(\mathrm{~A})$. Nesse intervalo apenas uma sala de aula estava no nível aceitável de conforto, ou seja, $97,30 \%$ das salas avaliadas encontravam-se fora dos limites padrão aceitáveis exigidos pela NBR 10.152 (ABNT, 1987). Nesse contexto de elevados níveis de pressão sonora, o professor tem, impreterivelmente, que aumentar a intensidade vocal no mínimo em +10 ou $+20 \mathrm{~dB}$, o que implica em um esforço vocal de, aproximadamente, até $30 \mathrm{~dB}(\mathrm{~A})$ para sobrepor a voz ao ruído de fundo. Assim, para que o último aluno da sala compreenda a mensagem passada pelo professor, é necessário um esforço vocal além do que as pregas vocais suportam, o que diminui a inteligibilidade de fala do professor. Este esforço para o docente implica no desenvolvimento de patologias como nódulos vocais, que irão interferir diretamente no seu desempenho, com consequências na sua produtividade, provocando afastamentos e onerando a Prefeitura Municipal de João Pessoa (PB).

\section{Artigo recebido em 03/02/2009 Aprovado para publicação em 28/06/2009}

\section{REFERÊNCIAS}

ANJOS, M. L. Incidência de disfonia no professor. Salvador, 1999. Monografia (Especialização em Fonoaudiologia.) - Centro de Especialização em Fonoaudiologia Clínica - CEFAC.

AMERICAN NATIONAL STANDARDS INSTITUTE - ANSI/ASA S12.60. Acoustical Performance Criteria, Design Requirements and Guidelines for Schools. [S.I.]: Acoustical Society of America, 2002.

ASSOCIAÇÃO BRASILEIRA DE NORMAS TÉCNICAS - ABNT. NBR 10.152. (NB - 95). Níveis de ruído para conforto acústico. Rio de Janeiro, 1987.

ASSOCIAÇÃO BRASILEIRA DE NORMAS TÉCNICAS - ABNT. NBR 10151. Avaliação do ruído em áreas habitadas visando o conforto da comunidade. Rio de Janeiro, 2000.

BEHLAU, M. et al. Voz prifissional fonoaudiológica. In: BEHLAU, M. Voz: o livro do especialista. Rio de Janeiro: Revinter, 2005.

BEHLAU, M.; PONTES, P. Avaliação e tratamento das disfonias. São Paulo: Lovise, 1995.

BIES, D. A.; HANSEN, C. H. Engineering noise control: theory and practice. 2 ed. New York: Spon Press - Taylor \& Francis Group, 2002.
BRASIL. Portaria 3.214, de 8 de junho de 1978. Aprova as Normas Regulamentadoras (NR) do Capítulo V do Título II, da Consolidação das Leis do Trabalho, relativas à Segurança e Medicina do Trabalho. Anexo I - NR- 15. Brasília, 1978.

\section{CONSELHO NACIONAL DO MEIO AMBIENTE} - CONAMA. Resolução 001, de 08 de março de 1990. Diário Oficial da União, de 02 de Abril de 1990, Seção I, Pág. 6.408.

DEUTSCHES INSTITUT FÜR NORMUNG (Germany). Schallschutz in schullen: DIN 18041. Germany, 1998.

ENIZ, A.; GARAVELLI, S. S. L. A contaminação acústica em ambientes escolares devido aos ruídos urbanos no Distrito Federal, Brasil. Holos Environment, v. 6, n. 2, p. 137, 2006. ISSN: 15198421(CD-ROM). ISSN: 1519-8634 (on-line).

EVANS, G. W.; MAXWELL, E. L. The Effects of Noise on Pre-Scholl Childreen's Pre-Reading Skills. Journal of Environmental Psychology, v. 20, p. 91-97, 2000.

FABIANO, S.; BRASOLOTO, A. Efeitos acústicos do uso profissional da voz pelo professor. (resumo). Laringologia e voz hoje. In: Temas do IV Congresso Brasileiro de Laringologia e Voz. [S,I.]: Revinter, 1998. p. 399.

FERNANDES, J. C. Inteligibilidade Acústica da Linguagem. Belo Horizonte: SOBRAC, 2000.
54 p. (Apostila do Curso de Inteligibilidade Acústica da Linguagem oferecido durante o XIX Encontro da SOBRAC).

IIDA, I. Ergonomia. Projeto e Produção. São Paulo: Ed. Edgard Blucher LTDA, 1990.

LUBMAN, D.; SUTHERLAND, L. C. Good classroom acoustics in a good investiment. Classroom Acoustics, p. 1-2, 2003. (Papers).

MENEGON, L. D. O ruído nas escolas e os problemas de saúde gerados a longo prazo de exposição. Bauru, SP, 2005. Monografia (Especialização em Engenharia de Segurança do Trabalho) - Universidade de São Paulo - USP.

NÁBĚLEK, A.; NÁBĚLEK, I. Acústica da sala e a percepção da fala. In: KARTZ, J. Tratado de audiologia clínica. São Paulo: Manole, 1997. p. $617-30$.

NEPOMUCENO, L. A. Elementos de acústica física e psicoacústica. São Paulo: Editora Edgar Blücher, 1994

NETO, J. G. Jornal O Estado de São Paulo, 22 de abril de 2001.

PENTEADO, R.; PEREIRA, I. A Voz do Professor: Relações entre Trabalho, Saúde e Qualidade de 
Vida. Revista Brasileira de Saúde Ocupacional, v. 25, n. 95, p. 109-130, 1996.

PEREIRA, A. Saúde vocal. Comunicação UNIFESP. Jornal da Paulista, ano 15, n. 169 julho 2002. Disponível em: http://www.unifesp. br/comunicacao/jpta/ed169/pesquisa1.htm.

PEARSONS, K. S.; BENNET, R. L.; FIDELL, S. Speech levels in varions noise environments. Springfield: National Information Service PB, 1977. p. 270-053.

PIMENTEL-SOUZA, F. Efeitos da poluição sonora no sono e na saúde em geral - ênfase urbana. Revista Brasileira de Acústica e Vibrações, v. 10, p. 12-22, 1992. Disponível em: http://www.ufmg.br/lpf/2-1. Acesso em: 21 de agosto de 2005.

ROMAN, M. New acoustical standards for classrooms. Disponível em: www.mbinet.org. Acesso em: 20 de maio de 2005.
SANTOS, M.; SLAMA, J. Ruído no ambiente escolar: Causas e conseqüências. In: ENCONTRO NACIONAL DE CONFORTO NO AMBIENTE CONSTRUÍDO - ENCAC/93, 2, 1993, Florianópolis, 1993. Anais... p. 301-306.

SANTOS, U. P. S. Ruído: riscos e prevenção. 3 ed. São Paulo: Hucitec, 1999.

SEEP, B. Acústica de Salas de Aulas. Revista de Acústica e Vibrações, n. 29, julho 2002.

SILVA, P. Os efeitos "pernilongo e cascata". Revista Acústica e Vibrações, v. 9, p. 19-25, junho 1991.

SOCINI, F.; COSTA, M. J.; OLIVEIRA, T. M. T. Queixa de dificuldade para reconhecer a fala $X$ limiares de reconhecimento de sentenças no ruído em normo-ouvintes com mais de 50 anos. Pancast. Revista Fono Atual, ano 6, n. 26, p. 4-11, 2003. ISSN 1517-0632.

SOUZA, L. C. L. Acústica arquitetônica. São Paulo: Bauru, 2003.

VONO-COUBE, C. Z.; BEVILACQUA, M. C.; FERNANDES, J. C. Ruído em escola. Bauru: HRAC-USP, 1999. 17 p. (Cadernos de Audiologia, 4).

WORLD HEALTH ORGANIZATION - WHO. Guidelines for community noise. London, UK, 1999. Disponível em: http//:www.who.int/ destore/peh/noise/guidelines2.html. Acesso em: 11 novembro 2008.

World Health Organization - WHO. Noise, environmental health criteria. Geneva, 1980. Disponível em: http//:www.inchem.org/documents/ehc/ehc012.html. Acesso em: 11 novembro 2008.

\section{AGRADECIMENTOS}

Agradecemos à Associação Brasileira de Engenharia de Produção (ABEPRO) pelo incentivo à pesquisa e pela oportunidade concedida na publicação deste trabalho. É importante ressaltar o apoio dado pelo Secretário de Educação da Prefeitura Municipal de João Pessoa bem como de todos os alunos e professores participantes dessa pesquisa; aos diretores das escolas Municipais, aos alunos dos cursos de Graduação em Engenharia de Produção Mecânica da Universidade Federal da Paraíba, e ao apoio dado pelo Programa de Pós-Graduação em Engenharia de Produção da mesma universidade, pessoas que foram importantes nos processos de seleção das escolas participantes, coleta e análise de dados dessa pesquisa.

\section{SOBRE OS AUTORES}

\section{Valéria de Sá Barreto Gonçalves}

Universidade Federal da Paraíba - UFPB

João Pessoa, PB, Brasil.

E-mail: lelajp@terra.com.br

\section{Luiz Bueno da Silva}

Universidade Federal da Paraíba - UFPB

João Pessoa, PB, Brasil.

E-mail: bueno@ct.ufpb.br

\section{Antonio Souto Coutinho}

Universidade Federal da Paraíba - UFPB

João Pessoa, PB, Brasil.

E-mail: coutinho@ct.ufpb.br 